Research Paper

\title{
In vitro Effects of Lipopolysaccharide and Stress Hormones on Phagocytosis and Nitric Oxide Production by Enriched Head Kidney Macrophage Cultures in the Catfish Heteropneustes fossilis
}

\author{
R KUMAR and K P JOY ${ }^{1, *}$ \\ Department of Zoology, Centre of Advanced Study, Banaras Hindu University, Varanasi 221 005, India \\ ${ }^{1}$ Present address: Department of Biotechnology, Cochin University of Science and Technology, Kochi \\ 682022 , India
}

(Received on 04 September 2017; Revised on 22 November 2017; Accepted on 25 November 2017)

\begin{abstract}
Head kidney (HK) is the embryonic pronephric kidney retained in adult teleosts and contains the adrenal homologues (interrenal and chromaffin cells) and hemopoietic tissue. The adrenal homologues secrete the stress hormones glucorticoids (cortisol) and catecholamines, and the hemopoietic tissue is a major source of monocytes/macrophages and neutrophils that serve as the first line of defence against invading pathogens. In the present study, head kidney macrophage-enriched preparations of Heteropneustes fossilis were used to demonstrate the dynamics of phagocytosis and nitric oxide (NO) production in the presence of lipopolysaccharide (LPS; bacterial toxin), the synthetic glucocorticoid dexamethasone and/or catecholamines. The incubation of enriched macrophage cultures with LPS for $6 \mathrm{~h}$ at $20^{\circ} \mathrm{C}$ stimulated phagocytosis of yeast cells and fluorescent latex beads. On the other hand, the cortisol agonist dexamethasone $(10 \mathrm{nM})$ inhibited phagocytosis of yeast cells and latex beads under similar conditions. LPS stimulated inducible NO synthase (iNOS)-like expression in the macrophage cultures, which was inhibited by dexamethasone in co-incubations. Complementary to the iNOS expression, LPS stimulated NO production (nitrite level), which was inhibited by the NO synthase inhibitor L-NMMA. Dexamethasone inhibited basal as well as the LPS-induced stimulation of NO. The catecholamines epinephrine and norepinephrine did not alter the basal NO level but inhibited the LPS-induced stimulation of NO. Dopamine stimulated NO production only at a higher concentration. The results provide evidence for the existence of an endocrine-immune interaction at the level of the head kidney to modulate macrophage activity and immune functions in the catfish.
\end{abstract}

Keywords: Head Kidney Macrophages; Catecholamines; Dexamethasone; Endocrine-Immune Interaction

\section{Introduction}

In fish, the innate immune response is the first line of defence against invading pathogens, executed by phagocytes comprising of neutrophils, monocytes and macrophages (Secombes and Fletcher, 1992; Magor and Magor, 2001). Neuroendocrine and autonomic nervous systems modulate immune functions (Castillo et al., 2009; Verburg-van Kemenade et al., 2011; Nardocci et al., 2014). The head kidney (HK) is the embryonic pronephric kidney containing endocrine (interrenal and chromaffin cells) and immune (macrophages and granulocytes) tissues and serves as an anatomical site for endocrine-immune interactions in fish (Verburg-van Kemenade et al.,
1994, 2011; Kumar et al., 2016).

Macrophages and neutrophils release extracellular traps that kill pathogens (Pijanowski et al., 2015). Phagocytosis is stimulated in the presence of bacterial toxins like lipopolysaccharide (LPS) through the mediation of nitric oxide (NO), reactive oxygen species (ROS), proinflammatory cytokines and chemokines (Pressley et al., 2005; Jensch-Junior et al., 2006; Kalgraff et al., 2011; Verburg-van Kemenade et al., 2011). The head kidney hemopoietic tissue, which surrounds the endocrine tissues, contain not only free moving macrophages, but also macrophage-aggregates called melano-macrophage centres (MMCs) involved in various steps in

*Authorfor Correspondence: E-mail: keerikkattilpailyjoy@yahoo.com 
phagocytosis, storage, detoxification of bacteria and alien material, and recycling of exogenous and endogenous materials that lead to the formation of melanin, lipofuscin and haemosiderin deposits (Matsche and Grizzle, 1999; Fishelson, 2006; Vigliano et al., 2006; Kumar et al., 2016). Free macrophages and macrophage-aggregates together take part in phagocytosis and help in removing the pathogenic microorganisms.

Macrophages employ NO and ROS in the defence mechanism against invading bacteria and other pathogens (Barroso et al., 2000; Aktan, 2004; Ishibe et al., 2009; Kalgraff et al., 2011; Yang et al., 2013). NO is produced by a wide range of cell types and the reaction is catalyzed by the $\mathrm{Ca}^{2+}$-independent enzyme NO synthase (NOS) (Barroso et al., 2000; Saeij et al., 2000; Aktan, 2004). Endothelial (eNOS, membrane bound) and neuronal (nNOS, soluble) NOS do not require any induction for the stimulation as they can be expressed constitutively in any cell type but inducible (iNOS, soluble) requires some induction for its expression, like bacterial products (Aktan, 2004). Inducible NOS is activated in a number of cells like macrophages, monocytes, neutrophils, dendritic cells and other lymphocytes and can be induced by LPS, thereby producing pro-inflammatory cytokines like interleukin- $1 \beta$ (IL-1 $\beta$ ) and tumor necrosis factor- $\alpha$ (TNF- $\alpha$ ), NO and ROS (Barroso et al., 2000). Inducible NOS can be also induced by different cytokines so that $\mathrm{NO}$ serves a central role in immune mechanisms (Yang et al., 2013). NO production in macrophages by LPS stimulation has been demonstrated in goldfish (Carassius auratus) and rainbow trout (Oncorhynchus mykiss) but in some fish like common carp (Cyprinus carpio) and goldfish, macrophage-activating factors like interferon- $\gamma$ (IFN$\gamma)$ can synergistically stimulate NO production (Neumann et al., 1995; Laing et al., 1999; Saeij et al., 2000; Arts et al., 2010; Pijanowski et al., 2015). In Heteropneustes fossilis, intraperitoneal injections of LPS increased the activity of iNOS in liver, kidney, heart, gills, muscle and brain and affect homeostasis (Choudhury and Saha, 2016).

Glucocorticoids (cortisol) and catecholamines (epinephrine and norepinephrine) are stress hormones secreted by the interrenal and chromaffin cells, respectively (Bonga, 1997; Reid et al., 1998; Mommsen et al., 1999; Weyts et al., 1999) and suppress immune functions. Cortisol suppresses immune responses in striped bass, rainbow trout, goldfish and carp (Kawano et al., 2003). Acute and chronic stress has been shown to suppress the responsiveness of the immune system (Chi et al., 2003; Nardocci et al., 2014). Thus, the fish head kidney is a unique model, not found in other vertebrates, for investigating endocrine (stress hormone) and immune interactions.

The main objective of the present investigation was to study endocrine-immune interactions at the level of the catfish head kidney. For this, the HK macrophages were isolated, cultured and phagocytic activity was demonstrated in the presence of LPS, a known immuno stimulant and dexamethasone, a synthetic glucocorticoid (cortisol agonist) and a known immuno suppressor. Secondly, effects of LPS and dexamethasone on iNOS expression and NO production were demonstrated in primary cultures of macrophages. Thirdly, effects of catecholamines (dopamine, norepinephrine and epinephrine), which are markers of adrenomedullary-sympathetic system, on NO production by cultured macrophages were studied and are presented here.

\section{Material and Methods}

\section{Chemicals and Reagents}

Dexamethasone, lipopolysaccharide (LPS, Escherichia coli, 0127: B8, purified by phenol extraction, impurities: $<3 \%$ of protein), latex fluorescent red beads ( $0.5 \mu \mathrm{m}$ mean particle size), percoll, triton-X 100, epinephrine (E), norepinephrine (NE), dopamine (D), and $\mathrm{N}^{\omega}$-mono methyl-L-arginine (L-NMMA), MS222, and fluorescent (FITC)-tagged secondary anti-rabbit antibody were purchased from Sigma-Aldrich, New Delhi, India. NOS-2 rabbit polyclonal antibody (N-20: sc-651; Santa Cruz Biotechnology, Inc) was purchased through local suppliers. Fetal bovine serum (FBS), Leibovitz L-15 medium, tissue culture flasks for adherent cells (surface area $12.5 \mathrm{~cm}^{2}$; total volume $25 \mathrm{~mL}$ ) and syringe-driven filter (nylon hydrophilic membrane, pore size $0.45 \mu \mathrm{m}, 30 \mathrm{~mm}$ diameter) were purchased from HiMedia Laboratories Pvt. Ltd, Mumbai, India. NNaphthylethylenediamine dihydrochloride and bovine serum albumin (BSA) were purchased from Sisco Research Laboratories (SRL) Pvt. Ltd., Mumbai, 
India. All other chemicals were of analytical grade and purchased from E. Merck, New Delhi, India.

\section{Animals}

The experiments were conducted as per the guidelines of the Animal Ethics Committee of Banaras Hindu University, Varanasi, India. All care was taken to prevent cruelty of any kind on animals. Adult live catfish (Heteropneustes fossilis) were purchased from Chaukaghat fish market in Varanasi during gonad-resting phase (December-January) of the annual reproductive cycle. In the laboratory, the fish were selected according to size and sex, and acclimatized for a week in cement tanks in the animal house. The fish were maintained at normal photoperiod (12 h L: $12 \mathrm{~h} \mathrm{D}$ ), ambient temperature $\left(22.5 \pm 2^{\circ} \mathrm{C}\right)$; and $\mathrm{pH}$ of $7.2 \pm 0.2$. The fish were fed daily with boiled egg white ad libitum. Few fish were sacrificed randomly and ovaries were dissected to check the ovary condition. The immature ovaries were translucent and pink-red in color. Sexually mature female fish (30-35 g) were used in the experiments.

\section{Preparation of Culture Medium}

Leibovitz (L-15) supplemented with $0.33 \%$ glucose was used as the incomplete L-15 medium. Complete Leibovitz medium was prepared by adding 5\% FBS and $100 \mu \mathrm{g} / \mathrm{mL}$ streptomycin to the incomplete L-15 medium. It was filtered with sterilized syringe-driven filters having a nylon hydrophilic membrane of pore size $0.45 \mu \mathrm{m}$ and $30 \mathrm{~mm}$ diameter and was stored at $4^{\circ} \mathrm{C}$ under sterile conditions.

\section{Macrophage Isolation}

Macrophages were isolated, as described previously (Braun-Nesje et al., 1982; Sarmento et al., 2004) with some modifications. Fish were anesthetized in 3aminobenzoic acid ethyl ester (MS-222) at a concentration of $0.2 \mathrm{~g} / \mathrm{L}$ for $5 \mathrm{~min}$ and sacrificed by decapitation. The head kidneys were removed aseptically and kept in phosphate buffered saline (PBS) buffer ( $\mathrm{pH} \mathrm{7.4)}$ at $4^{\circ} \mathrm{C}$. Cell suspensions were made in sterilized glass Petri plate or cavity glass by pressing the head kidneys against cleaned toothed forceps or pipetting in the PBS buffer and passed through a $50 \mu \mathrm{m}$ nylon mesh using incomplete Leibovitz (L-15) medium under sterile conditions. The single cell suspension was washed in the L-15 incomplete medium two times by centrifuging at 2000 rpm for $2 \mathrm{~min}$. The resulting cell suspension was placed on a percoll density gradient (1:1 ratio in incomplete medium). The gradient was centrifuged at $2000 \mathrm{rpm}$ for $20 \mathrm{~min}$ at $20^{\circ} \mathrm{C}$. The interface cells were collected and were transferred to a separate tube and washed twice in the PBS buffer at $2000 \mathrm{rpm}$ for $3 \mathrm{~min}$ to remove percoll. The cells were again washed in incomplete L-15 medium at $2000 \mathrm{rpm}$ for $3 \mathrm{~min}$ at $20^{\circ} \mathrm{C}$. The viability of the cells was determined by trypan blue $(0.4 \%)$ dye exclusion method $\left(2 \times 10^{7}\right.$ cells/ $\mathrm{mL})$. The cells were incubated in complete L-15 medium supplemented with $5 \%$ FBS and $100 \mu \mathrm{g} / \mathrm{mL}$ streptomycin for $8 \mathrm{~h}$ so that the cells adhered to the surface of the tissue culture flask. The non-adherent cells which included lymphocytes and small round nonadherent monocytes in the medium were washed out to ensure maximum macrophage concentration. Differential staining and counting showed about $86 \%$ of the adhered cell population as macrophages and the remaining as neutrophilic granulocytes and adherent monocytes. Fresh complete L-15 medium was added to the culture and was maintained in a $5 \%$ $\mathrm{CO}_{2}$ incubator at $20 \pm 2^{\circ} \mathrm{C}$. After the incubation, viable adherent cells were detached using a cell scrapper and the number of detached viable macrophages was determined in a hemocytometer using the standard trypan blue dye exclusion test. More than $98 \%$ cells were viable and were used for subsequent experiments.

\section{Culture of Enriched Macrophages}

Glass coverslips of $18 \mathrm{~mm}$ diameter were dipped in $90 \%$ alcohol for $5 \mathrm{~min}$ and were carefully dried over a flame for a few seconds until they dried up. The cover slips were kept in a laminar chamber for a while to cool and placed carefully into the 12-well plate. They were centred so that no contacts occurred between their edges and the culture plates. One $\mathrm{mL}$ of cell suspension $\left(1.5 \times 10^{6}\right.$ cells $\left./ \mathrm{mL}\right)$ in L-15 medium was added over each cover slip. The 12 -well plate was placed in the $\mathrm{CO}_{2}$ incubator for $8 \mathrm{~h}$ at $20^{\circ} \mathrm{C}$ till the cells adhered to the coverslips. Culture medium from each well was gently aspirated so that the adhered cells were not disturbed. The cells were rinsed with the PBS buffer two times at room temperature (RT). Fresh complete medium was added to the cell culture plate. 


\section{Determination of Phagocytosis}

\section{Phagocytosis of Yeast Cells}

In order to study the endocrine-immune interaction, the cultured macrophage preparations were exposed to LPS (an immune stimulant) or dexamethasone (immune suppressor) treatments in 12-well plates. Cells $\left(1.5 \times 10^{6}\right.$ cells $\left./ \mathrm{mL}\right)$ in L-15 medium were treated with LPS ( $1 \mu \mathrm{g} / \mathrm{mL}$, see below) or dexamethasone (10 nM, see below) for $6 \mathrm{~h}$. Control cells were given the equivalent amount of the vehicle in the medium. Yeast (Saccharomyces cerevisiae) extract was dissolved in the PBS buffer and was heated at $60^{\circ} \mathrm{C}$ for $5 \mathrm{~min}$ to make a homogenous yeast solution. Based on the macrophage count, the yeast cell suspension was adjusted so that the number of yeast added was 10 times the number of macrophages. After the incubation, the adherent macrophages were incubated with $100 \mu \mathrm{L}$ of yeast suspension $\left(2 \times 10^{7}\right.$ yeast cells/ $\mathrm{mL}$ ) in L-15 medium in 12 -well plates for $2 \mathrm{~h}$ at $20^{\circ} \mathrm{C}$ in a $\mathrm{CO}_{2}$ incubator. The number of attached macrophages or yeast per cover slip, the number of macrophages phagocytozing and the number of yeast cells per macrophages were determined by direct microscopy. Macrophages and yeast cells were counted at $25 \mathrm{X}$ objective to calculate the phagocytic activity in percentage (Amar et al., 2004). The calculation took into consideration the number of macrophages that were phagocytic and phagocytosed yeast cells out of total number of macrophages.

$$
\begin{aligned}
& \text { Number of macrophages } \\
& \text { phagocytosed/phagocytic }
\end{aligned}
$$

Total number of macrophages x 100

\section{Phagocytosis of Fluorescent-tagged Latex Beads}

In a second experiment, phagocytosis was investigated using fluorescent-tagged latex beads. Adherent macrophages $\left(1.5 \times 10^{6}\right.$ cells $\left./ \mathrm{mL}\right)$ were treated with LPS $(1 \mu \mathrm{g} / \mathrm{mL})$ or dexamethasone $(10 \mathrm{nM})$ in a $12-$ well plate for $6 \mathrm{~h}$, as described above. After the incubation, the macrophages were incubated with 20 $\mu \mathrm{L}$ of commercially available latex fluorescent red beads $(0.5 \mu \mathrm{m}$ mean particle size $)$ in $\mathrm{L}-15$ medium in the 12-well plate for $2 \mathrm{~h}$ at $20^{\circ} \mathrm{C}$ in a $\mathrm{CO}_{2}$ incubator under dark in a humidified chamber. Extra beads were washed out with the PBS buffer thrice. The coverslips were mounted on glycerol. Differential interference contrast (DIC) and fluorescent images were taken in a Carl Zeiss LSM 780 confocal microscope.

Immunocytochemical Staining of NOS-2 in LPSand Dexamethasone-Treated Macrophage Preparations

Two hundred $\mu \mathrm{L}$ of cell suspension in the L-15 medium was added over each coverslip. The plate was placed in the $\mathrm{CO}_{2}$ incubator for $8 \mathrm{~h}$ at $20^{\circ} \mathrm{C}$ until macrophages adhered to the coverslip. Culture medium from each well was gently aspirated so that the adhered cells were not disturbed. The cells were rinsed with the PBS buffer two times at RT and fresh medium was added. The adhered cells were stimulated with LPS $(1 \mu \mathrm{g} / \mathrm{mL}$ in the PBS buffer) or treated with both LPS and dexamethasone $(10 \mathrm{nM}$; dissolved in $10 \mu \mathrm{L}$ ethanol and diluted with $90 \mu \mathrm{L}$ PBS buffer) for $16 \mathrm{~h}$. Control preparations were given vehicle treatment.

After the incubation, the adhered cells on the coverslips were rinsed carefully with PBS buffer $(\mathrm{pH}$ 7.2) two times at RT in the plate. The cells were fixed with 4\% paraformaldehyde in 1 X PBS for 20 min at RT and washed two times with the PBS buffer. To permeabilize the cells, the coverslips were incubated with PBS buffer containing $0.25 \%$ Triton $\mathrm{X}-100$ for $10 \mathrm{~min}$. The coverslips were washed 3 times with the PBS buffer and then with $1 \%$ bovine serum albumin (BSA) for $1 \mathrm{~h}$ to block non-specific binding of the antibody. The adherent cells were incubated with NOS-2 rabbit polyclonal antibody $(1: 100)$ in the PBS buffer overnight in a humidified chamber at $4^{\circ} \mathrm{C}$ and then washed 3 times with the PBS buffer. The cells were then incubated with diluted FITC-tagged anti-rabbit secondary antibody (1:500) in the PBS buffer for $2 \mathrm{~h}$ in dark and washed with the PBS buffer 3 times. One drop of mountant containing DAPI was taken on a clean slide and the coverslips were mounted upside down. The preparations were examined under a Carl Zeiss LSM 780 confocal microscope and images were taken.

\section{Effects of LPS, Dexamethasone and Catecholamines on Macrophage NO Production Effect of LPS}

Time- and dose-dependent experiments were conducted to show the concentration- and timedependent stimulation of LPS on NO production. Macrophage cultures prepared separately from head 
kidneys $\left(3 \times 10^{5}\right.$ cells per $200 \mu \mathrm{L}$ in each well) were dispensed into 96 well plates in complete L-15 medium. They were incubated with different concentrations of LPS $(1,10$ or $20 \mu \mathrm{g} / \mathrm{mL})$ for 8,16 or $24 \mathrm{~h} \mathrm{(} \mathrm{n}=5$ fish per group). The culture was maintained in a $5 \% \mathrm{CO}_{2}$ incubator at $20^{\circ} \mathrm{C}$. In order to validate NO production, adherent macrophage cultures were additionally treated with the arginine analog inhibitor L-NMMA (1mM) (Barroso et al., $2000)$ alone or in combination with LPS $(1 \mu \mathrm{g} / \mathrm{mL})$ for $16 \mathrm{~h}$. The macrophage cultures were treated with L-NMMA immediately before the LPS addition (in the combination group of LPS and L-NMMA).

\section{Effect of Dexamethasone}

Dexamethasone was dissolved in $10 \mu \mathrm{L}$ ethanol and diluted with $90 \mu \mathrm{L}$ PBS buffer ( $\mathrm{pH}$ 7.4). Macrophage preparations cultured in complete L-15 medium were treated with dexamethasone in $10 \mathrm{nM}$ or $100 \mathrm{nM}$ concentrations for $8 \mathrm{~h}$ and $16 \mathrm{~h}$ ( $\mathrm{n}=5$ fish per group). In the second experiment, to study the effect of dexamethasone on LPS-induced NO production, the macrophage cultures were treated with a combination of dexamethasone $(10 \mathrm{nM})$ and LPS $(1 \mu \mathrm{g} / \mathrm{mL}$ in the PBS buffer) or dexamethasone (100 $\mathrm{nM})$ and LPS $(1 \mu \mathrm{g} / \mathrm{mL})$ for $16 \mathrm{~h}$.

\section{Effects of Catecholamines}

In this experiment, macrophage cultures were incubated with epinephrine (E, $1 \mathrm{nM}$ and $10 \mathrm{nM})$, norepinephrine (NE, $1 \mathrm{nM}$ and $10 \mathrm{nM}$ ) or dopamine (D, $1 \mathrm{nM}$ and $10 \mathrm{nM})$ for $16 \mathrm{~h}(\mathrm{n}=5$ fish per group). In order to study the effect of catecholamines on the LPS-induced NO production, the macrophage cultures were treated with LPS $(1 \mu \mathrm{g} / \mathrm{mL})$ and E $(10 \mathrm{nM}), \mathrm{NE}$ $(10 \mathrm{nM})$ or $\mathrm{D}(10 \mathrm{nM})$ for $16 \mathrm{~h}$.

\section{NO Assay}

Since NO is an unstable molecule and degrades to nitrate and nitrite, $\mathrm{NO}$ was measured using the method of Yamaguchi et al. (2001) with slight modifications. This method quantifies the nitrite content. After the incubation, the cell-free supernatant was assayed for nitrite using the Griess reagent. A hundred $\mu \mathrm{L}$ of the culture supernatant was placed in a fresh 96-well plate and mixed with $50 \mu \mathrm{L}$ of $0.1 \% N$-1-naphthylethylenediamine dihydrochloride and $50 \mu \mathrm{L}$ of $1 \%$ sulphanilamide prepared in $2.5 \% \mathrm{H}_{3} \mathrm{PO}_{4}$ at room temperature for $10 \mathrm{~min}$. Optical density was determined in a microplate reader at $570 \mathrm{~nm}(\mathrm{EPOCH}$, Bio Tek Instruments Inc, Highland Park, USA). Nitrite in the supernatant was calculated in molar concentrations by using a standard curve of sodium nitrite.

\section{Statistical Analysis}

The experiments were repeated five times and the data were expressed as means \pm SEM. The data were checked for homogeneity and normality and further analyzed by one- or two-way analysis of variance (ANOVA, $\mathrm{p}<0.001$ ), followed by Newman-Keuls' test $(p<0.05)$ for multiple group comparisons. The analysis was performed using a SPSS version 16 for Windows.

\section{Results}

\section{Phagocytosis of Yeast Cells}

Phagocytic activity was examined under a phase contrast microscope after treatment with LPS or dexamethasone. The macrophages engulfed yeast cells, which were seen within the macrophages. The PI was significantly high in the LPS-treated group and significantly low in the dexamethasone-treated group, as compared with the control (Fig. 1; $\mathrm{p}<0.001$, one way ANOVA; $\mathrm{p}<0.05$, Newman- Keuls' test).

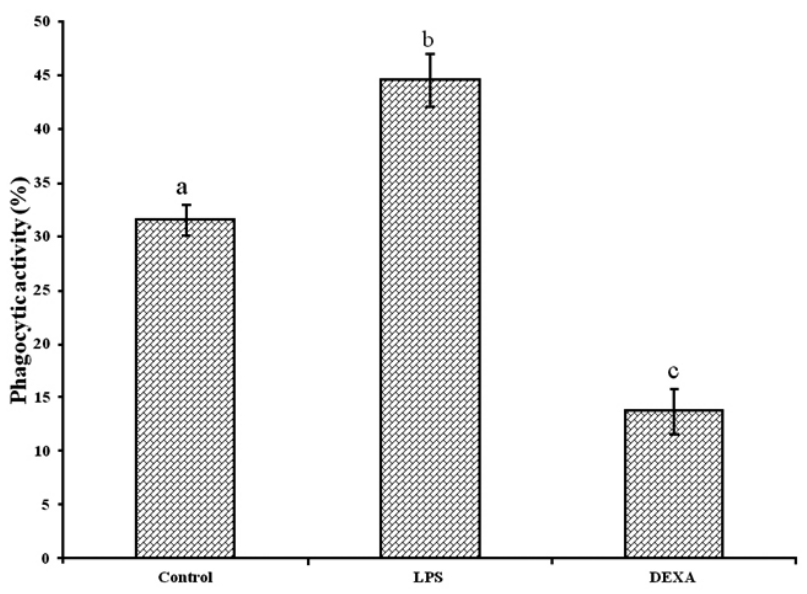

Fig. 1: In vitro effects of lipopolysaccharide (LPS) and dexamethasone (DEXA) on phagocytic activity (\%) of head kidney macrophages. Values are means \pm SEM. Data were analyzed by one way ANOVA $(p<0.001)$ and Newman-Keuls' test $(p<0.05)$. Groups bearing different letters are significantly different 


\section{Phagocytosis of Latex Beads}

In the control group, macrophages (DIC image, Fig. 2A) and latex beads (red fluorescence, Fig. 2B) were revealed under the confocal microscope. When the two images were merged (Fig. 2C), few latex beads were seen engulfed by the macrophages. In the LPStreated culture, the phagocytic activity of the macrophages was high (Fig. 2D,E,F), as compared with the control. On the other hand, in the dexamethasone-treated culture, macrophage activity was low, as evident from the less number of latex beads engulfed (Fig. 2G,H,I).

\section{Expression of iNOS}

In the control group, the presence of macrophages was indicated by the DAPI nuclear staining (Fig. 3A). The expression of iNOS was very weak (Fig. 3B), which was more evident after merging (Fig. 3C). When the macrophage cultures were stimulated with LPS $(1 \mu \mathrm{g} / \mathrm{mL})$ for $16 \mathrm{~h}$, a large number of macrophages showed iNOS-like immuno reactivity, as evident from the green fluorescence in the cytoplasm (Fig. 3E). The nuclei stained DAPI (Fig. 3D). The merged images showed differential staining of iNOS and DAPI clearly (Fig. 3F). When the

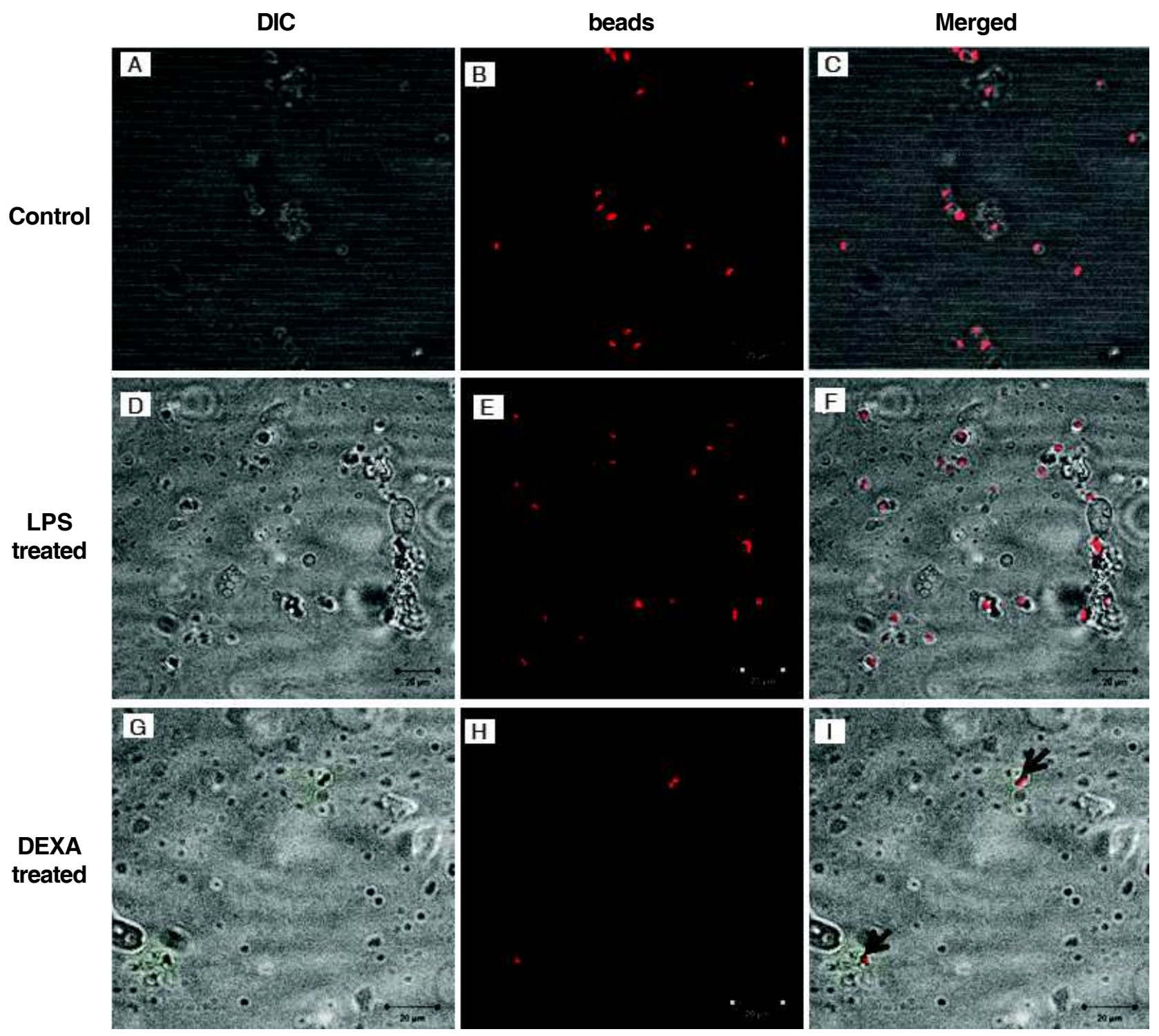

Fig. 2: Phagocytosis of fluorescent latex beads by macrophages incubated with LPS (D,E,F) and dexamethasone (G,H,I), as compared with the control (A,B,C). Fig. A,D,G in the left lane show DIC images. Fig. B,E,H in the middle lane show the latex beads in the culture engulfed by macrophages. Fig. $C, F, I$ in the right lane show the merged images. Magnification bar-20 $\mu \mathrm{m}$ 
macrophage cultures were treated with both LPS and dexamethasone $(10 \mathrm{nM})$ for $16 \mathrm{~h}$ (Fig. 3G,H,I), the iNOS expression was diminished both in the intensity of staining and number of macrophages. Dexamethasone treatment alone did not show the expression of iNOS (figure not shown).

\section{Effect of LPS on NO Production}

The LPS treatment caused significant dose- and timedependent effects on macrophage nitrite level (as a measure of NO) (Fig. 4; $<<0.001$; two way ANOVA $\left.\mathrm{F}_{\text {conc }}=140.54 ; \mathrm{F}_{\text {time }}=28.09\right)$. LPS elicited a dosedependent significant increase in the $1 \mu \mathrm{g} / \mathrm{mL}$ and 10 $\mu \mathrm{g} / \mathrm{mL}$ groups at $8 \mathrm{~h}$ and $16 \mathrm{~h}$. But the increase between $10 \mu \mathrm{g} / \mathrm{mL}$ and $20 \mu \mathrm{g} / \mathrm{mL}$ was not significant at any of the time interval. There was no significant difference between $16 \mathrm{~h}$ and $24 \mathrm{~h}$ in all the dose groups. Therefore, a dose of $1 \mu \mathrm{g} / \mathrm{mL}$ for $16 \mathrm{~h}$ was used for the LPS stimulation in further experiments.

When the macrophage culture was incubated with both LPS $(1 \mu \mathrm{g} / \mathrm{mL})$ and L-NMMA $(1 \mathrm{mM})$ for 16 h (Fig. 5), the LPS-induced production of nitrite was significantly inhibited compared to the LPS group $(\mathrm{p}<0.001$; one way ANOVA; $\mathrm{p}<0.05$; NewmanKeuls' test). L-NMMA did not alter the basal production of nitrite as compared with the control group.

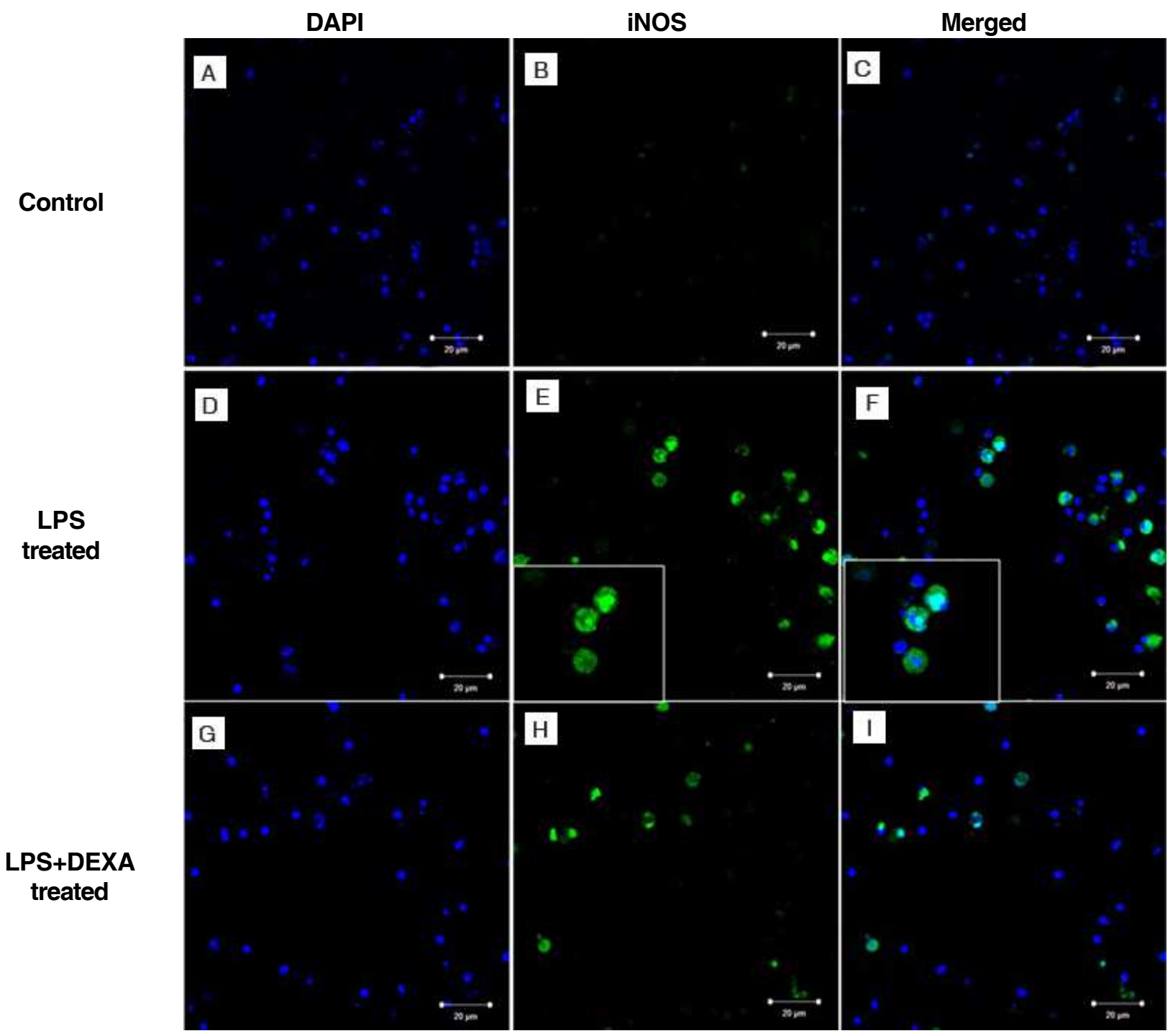

Fig. 3: Inducible NOS expression by macrophages in the presence of lipopolysaccharide (LPS) and LPS and dexamethasone (DEXA). Fig. A,B,C show control macrophages showing weak iNOS expression. Fig. D,E,F show a large number of iNOSexpressing macrophages when stimulated with LPS. Fig. G,H,I show few iNOS-expressing macrophages when incubated with both LPS and dexamethasone. FITC-NOS-2 staining.Magnification bar-20 $\mu \mathrm{m}$ 


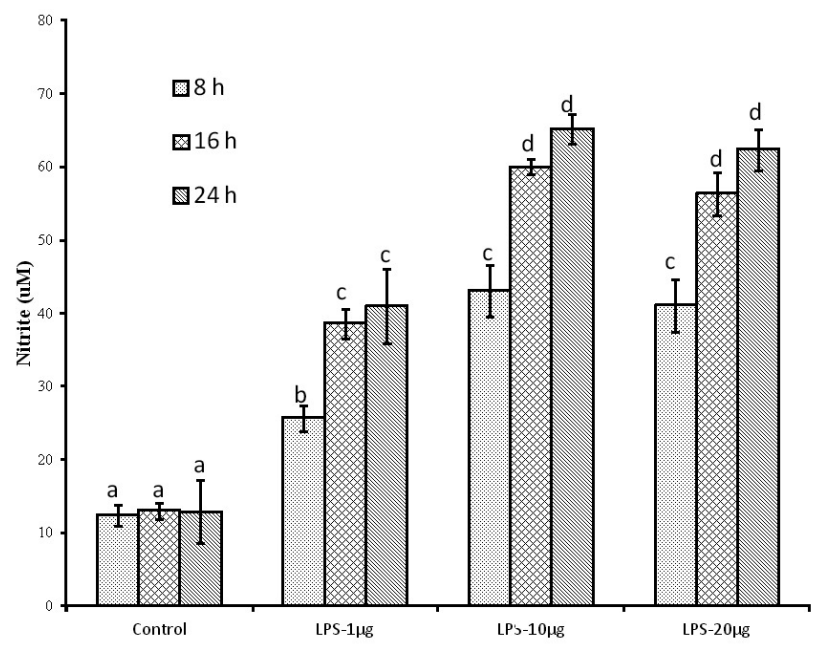

Fig. 4: In vitro effects of lipopolysaccharide (LPS) on nitrite production by macrophages. Values are mean \pm SEM of 5 replicate samples each. Data were analyzed by two way ANOVA $(p<0.001)$ and Newman-Keuls' test $(p<0.05)$. Groups bearing the same letters are not significantly different and those bearing different letters are significantly different

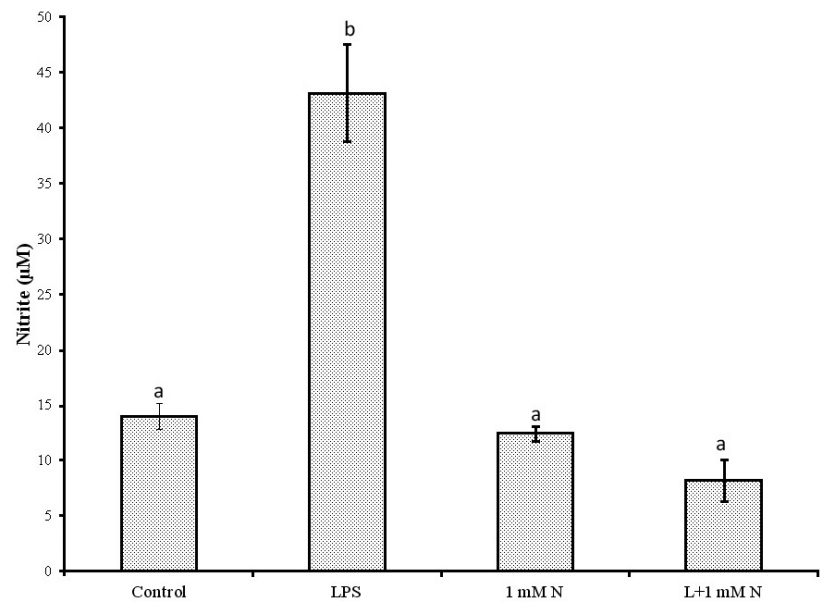

Fig. 5: In vitro effects of the NO inhibitor L-NMMA (N) and LPS + $\mathbf{N}$ on nitrite production by macrophages. Values are mean \pm SEM of 5 replicate samples each. Data were analyzed by one way ANOVA $(p<0.001)$ and Newman-Keuls' test $(\mathbf{p}<0.05)$. Groups bearing the same letters are not significantly different and those bearing different letters are significantly different

\section{Effect of Dexamethasone on NO Production}

The dexamethasone treatment produced a significant dose-dependent decrease in the nitrite level as compared with the control (Fig. $6 ; \mathrm{p}<0.001$; two way ANOVA, $\left.\mathrm{F}_{\text {conc }}=43.69 ; \mathrm{F}_{\text {time }}=1.66\right)$. When macrophage cultures were co-incubated with

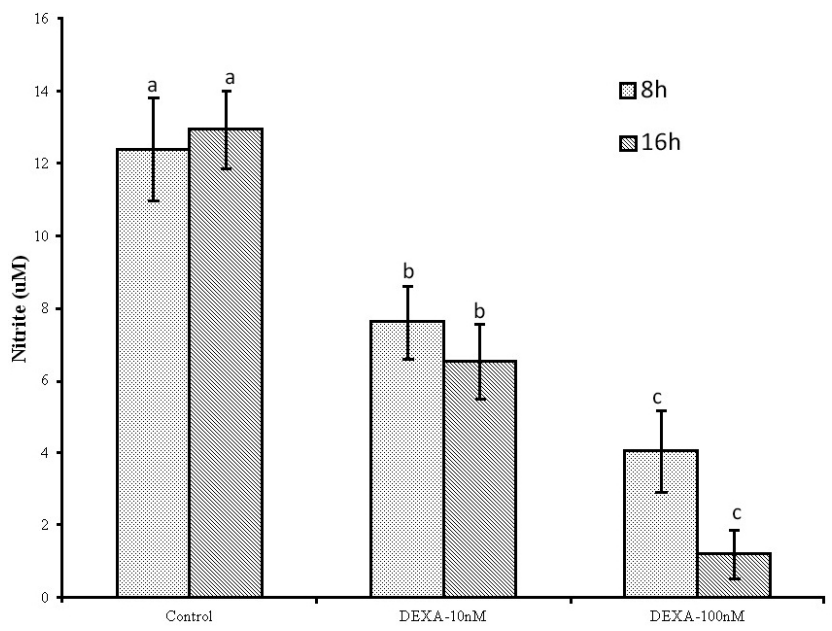

Fig. 6: In vitro effects of dexamethasone (DEXA) on nitrite production by macrophages for $8 \mathrm{~h}$ and $16 \mathrm{~h}$. Values are mean \pm SEM of 5 replicate samples each. Data were analyzed by two way ANOVA $(p<0.001)$, followed by Newman-Keuls' test $(\mathbf{p}<0.05)$. Groups bearing the same letters are not significantly different and those bearing different letters are significantly different

dexamethasone (10 $\mathrm{nM}$ or $100 \mathrm{nM})$ and LPS $(1 \mu \mathrm{g} /$ $\mathrm{mL}$ ) for $16 \mathrm{~h}$, both basal and LPS-induced increase in the nitrite level was inhibited in a concentrationdependent manner (Fig. 7).

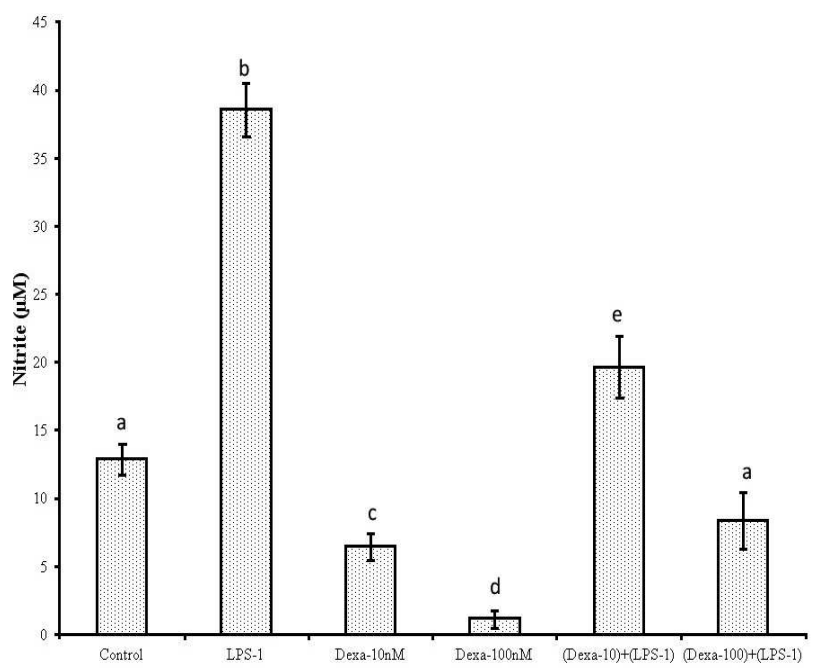

Fig. 7: In vitro nitrite production by macrophage cultures incubated for $16 \mathrm{~h}$ with LPS, dexamethasone (DEXA) and the combination of LPS and DEXA. Values are mean \pm SEM of 5 replicate samples each. Data were analyzed by one way ANOVA $(p<0.001)$ and NewmanKeuls' test $(p<0.05)$. Groups bearing the same letters are not significantly different and those bearing different letters are significantly different 


\section{Effects of Catecholamines on NO Production}

The incubation of macrophage cultures with different concentrations of catecholamines E, NE and D (1 $\mathrm{nM}$ and $10 \mathrm{nM}$ ) for $16 \mathrm{~h}$ did not alter the basal level of nitrite (Fig. 8) except for a significant increase in the $10 \mathrm{nM} D$ group. Under these conditions, LPS $(1 \mu \mathrm{g} /$ $\mathrm{mL})$ stimulated, and dexamethasone $(10 \mathrm{nM})$ inhibited the nitrite level significantly, as reported above. When the macrophage culture was co-incubated with LPS $(1 \mu \mathrm{g} / \mathrm{mL})$, and $\mathrm{E}(10 \mathrm{nM}), \mathrm{NE}(10 \mathrm{nM})$ or $\mathrm{D}(10 \mathrm{nM})$ for $16 \mathrm{~h}$, the LPS-induced increase in the nitrite was significantly inhibited by $\mathrm{E}$ and NE, but not by D (Fig. $9 ; \mathrm{p}<0.001$; one way ANOVA; $\mathrm{F}=16.76 ; \mathrm{p}<0.05$; Newman-Keuls' test).

\section{Discussion}

\section{Phagocytosis}

The head kidney macrophage preparations engulfed both yeast cells and latex beads efficiently in the presence of LPS. Though the phagocytic index was not calculated for the latex beads, they were found more efficiently internalized than the larger yeast cells. Macrophages from channel catfish (Ictalurus punctatus) efficiently phagocytosed and killed Edwardsiella ictaluri (Wise et al., 1993). In common carp, head kidney macrophages and neutrophilic granulocytes actively phagocytosed bacteria (Escherichia coli) and yeast cells; bacteria were more engulfed than the yeast cells (Verburg-van Kemenade et al., 1994). Goldfish monocytes/ macrophages were efficient in internalizing apoptotic bodies but neutrophils displayed a very limited capacity for their uptake (Rieger et al., 2012). In contrast, murine neutrophils displayed internalization of apoptotic bodies as efficiently as monocytes/ macrophages (Rieger et al., 2012). In the catfish macrophage preparations, since neutrophils are present in a small proportion, phagocytic activity by neutrophils may be minimal.

In the present study, we used dexamethasone, a synthetic analogue of cortisol, instead of the endogenous hormone to demonstrate the inhibitory effects of steroids on immune responses, as described in striped bass, rainbow trout and goldfish (Stave and Roberson, 1985; Wang and Bolosevic, 1995; Yamaguchi et al., 2001). In common carp, the macrophages treated with cortisol suppressed phagocytosis and the production of both NO and superoxide anion (Yamaguchi et al., 2001). Cortisol exerts both positive and negative effects on immune function and disease resistance (Maule et al., 1989; Tort, 2011; Verburg-van Kemenade et al., 2011) and glucocorticoid receptors with high affinity and low capacity binding for cortisol was reported in carp neutrophils (Weyts et al., 1998a). Cortisol inhibited apoptosis in neurtrophils but induced apoptosis in Blymphocytes of common carp, stimulated with mitogens like LPS through a receptor-mediated mechanism (Weyts et al. 1998a, b). The cortisol effect was not evident in T cells under both stimulated and unstimulated conditions. In isolated head kidney cells of sea bream (Sparusauratus), cortisol (50 and 100 $\mathrm{ng} / \mathrm{mL}$ ) decreased the gene expression of both pro(TNF- $\alpha$, IL-1 $\beta$, IL-6) and anti- (TGF- $\beta 1$ ) inflammatory cytokines and the LPS-stimulated IL$1 \beta$ expression (Castillo et al., 2009). The suppressive effect of dexamethasone on phagocytosis is evident in the catfish macrophage preparations, stimulated with LPS. Less number of macrophages engulfed yeast and latex beads in the presence of dexamethasone. Dexamethasone is structurally and functionally similar to cortisol and behaves similarly in feedback and receptor binding activities (Cole et al., 2000; Holland et al., 2002).

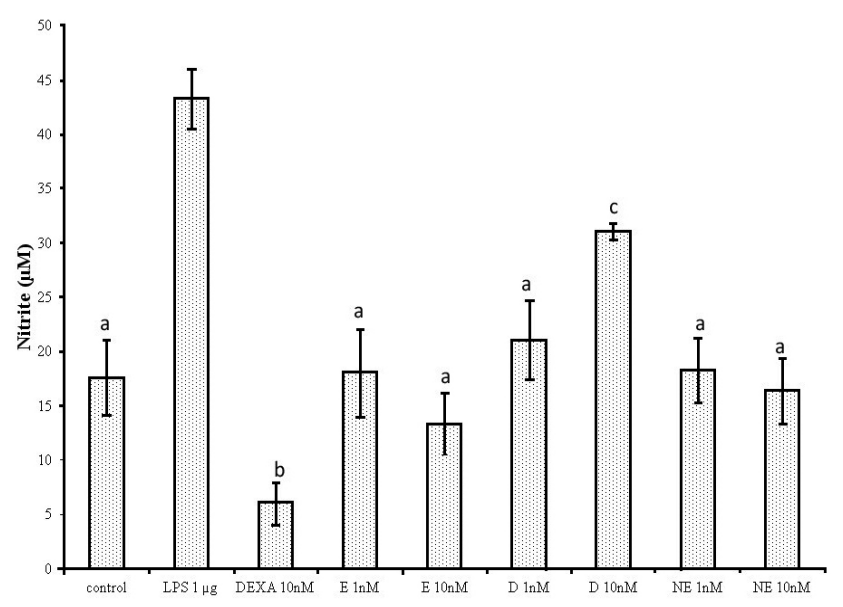

Fig. 8: In vitro effects of epinephrine (E), norepinephrine (NE) and dopamine (D) on nitrite production by macrophages. For comparison, effects of LPS and DEXA are shown. Values are mean \pm SEM of 5 replicate samples each.Data were analyzed by one way ANOVA $(p<0.001)$ and Newman-Keuls' test $(p<0.05)$. Groups bearing the same letters are not significantly different and those bearing different letters are significantly different 


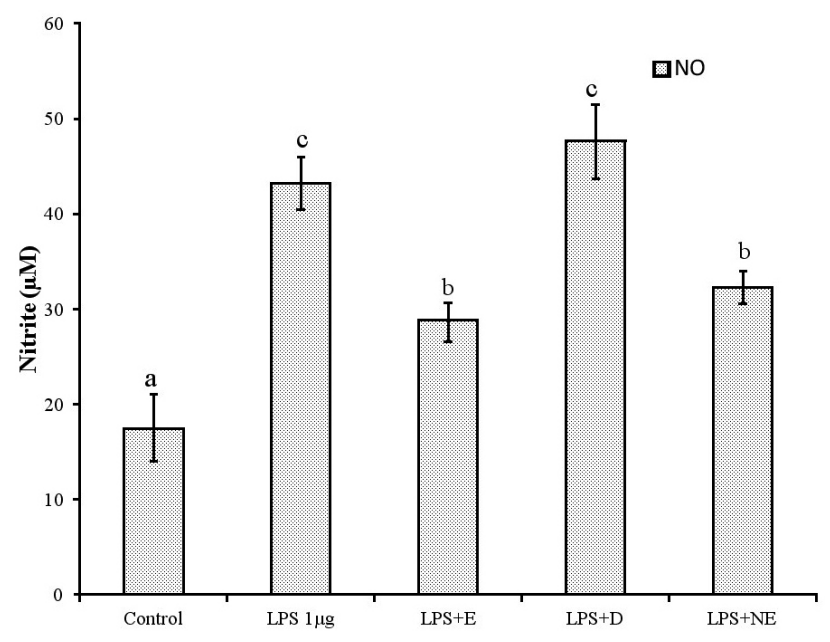

Fig. 9: In vitro effects of epinephrine $\left(\begin{array}{llll}E & 10 & \mathrm{nM}\end{array}\right)$, norepinephrine (NE 10nM) and dopamine (D $10 \mathrm{nM})$ on nitrite production by macrophages in the presence of LPS. Values are mean \pm SEM of 5 replicate samples each. Data were analyzed by one way ANOVA (p < $0.001)$ and Newman-Keuls' test $(p<0.05)$. Groups bearing the same letters are not significantly different and those bearing different letters are significantly different

\section{NO Production}

The LPS concentrations at 1,10 and $20 \mu \mathrm{g} / \mathrm{mL}$ significantly increased nitrite production at $8 \mathrm{~h}, 16 \mathrm{~h}$ and $24 \mathrm{~h}$. The NO production was maximal in the LPS $10 \mu \mathrm{g} / \mathrm{mL}$ at $16 \mathrm{~h}$; the $20 \mu \mathrm{g} / \mathrm{mL}$ did not produce further significant increase at any of the duration. In the catfish, the effective concentration may be $1 \mu \mathrm{g} /$ $\mathrm{mL}$ or below and the exposure time may be $8 \mathrm{~h}$ or less, which suggest that the catfish macrophages may be more sensitive than reported in other teleosts. Due to high resistance to LPS toxicity, LPS renders immune responses in fishes at 1000-fold higher concentration than that in mammals (Mackenzie et al., 2010). The optimal LPS concentration required for NO production in macrophages isolated from the trout was in the range of $1-50 \mu \mathrm{g} / \mathrm{mL}$ (Fierro-Castro et al., 2012). However in Hoplias malabaricus, LPS at $1 \mathrm{ng} / \mathrm{mL}$ stimulated NO production significantly in the anterior kidney monocytes/macrophages (Ribas et al., 2014). In the common carp, dose-related differences were reported in tissues; LPS at $0.1 \mu \mathrm{g} /$ $\mathrm{mL}$ stimulated significantly NO release in head kidney monocytes/macrophages but a significant up regulation in neutrophils was obtained at LPS concentrations at and above $10 \mu \mathrm{g} / \mathrm{mL}$ (Pijanowski et al., 2015). A partially purified LPS, but not pure LPS, up regulated iNOS gene expression in neutrophils and macrophages/monocytes. In the catfish, LPS at $1 \mu \mathrm{g} /$ $\mathrm{mL}$ stimulated iNOS expression and nitrite level. A parallel stimulation in iNOS expression and NO release has been reported in rainbow trout (Barroso et al., 2000). Similarly, nitrite production was observed when macrophages of Japanese flounder (Paralichthys olivaceus) were exposed to Edwardsiella tarda (Ishibe et al., 2009).

In the catfish macrophage preparations, the $\mathrm{NO}$ inhibitor L-NMMA inhibited the LPS-induced NO production to the basal level, as has been reported in H. malabaricus (Ribas et al., 2014). L-NMMA did not inhibit basal nitrite level, indicating that the basal NO level may be due to constitutive expression of NOS and LPS stimulated only the inducible form of NOS. In turbot (Scophthalmus maximus), macrophages exhibited two different responses, LPSresponsive and LPS- non-responsive, in the production of NO (Tafalla and Novoa, 2000). The non-responsive macrophages responded to LPS when co-incubated with turbot macrophage-activating factor (MAF), turbot IFN- $\alpha, \beta$-like substances or human recombinant TNF- $\alpha$, indicating the presence of macrophage subtypes with different physiological activation status. In the gilthead seabream Sparus aurata, LPS failed to induce NO production but the induction occurred when MAF and LPS were used in the leucocyte culture (Mulero and Meseguer, 1998). IL-1 $\beta$ gene was highly expressed by purified macrophage monolayers and was up-regulated by LPS and lymphocyte-derived MAF stimulation (Pelegrin et al., 2001). In the common carp, IFN- $\gamma 2$, in combination with commercially available LPS (partially purified) or pure LPS synergistically up regulated iNOS gene expression and NO release by macrophages/ monocytes and neutrophils (Pijanowski et al., 2015). These authors proposed that IFN- $\gamma 2$ might activate TLR 4 or TLR2 to which pure LPS would bind to cause microbial recognition and innate and adaptive immune responses. The impurities in commercial LPS like peptidoglycans are responsible for LPS effects probably by acting through TLR 2 (Pijanowski et al., 2015; Mackenzie et al., 2010). In goldfish and African catfish (Clarias gariepinus), LPS could directly stimulate NO production (Neumann et al., 1995; Yin et al., 1997), as in H. fossilis. These results show that NO production by macrophages may be direct or indirect depending on species. Future studies should 
address, if pure LPS can stimulate directly NO production in the catfish.

Dexamethasone inhibited both basal and the LPS-induced NO production in a dose- and timedependent manner. Cortisol inhibits NO and superoxide production by macrophages in goldfish and carp (Radomski et al., 1990; MacMicking et al., 1997; Fast et al., 2008). Cortisol at $10 \mathrm{nM}$ significantly inhibited the function of carp phagocytic cells such as the production of superoxide and phagocytosis in vitro (Yamaguchi et al., 2001). In H. malabaricus, dexamethasone $(0.3$ and $3 \mu \mathrm{g} / \mathrm{mL})$ significantly inhibited the LPS-induced NO production by suppressing NOS activity (Fierro-Castro et al., 2012). In the catfish, dexamethasone treatment suppressed the LPS-induced iNOS expression and NO production. Cortisol receptors have been described in fish immune cells and modulate pro- and anti-inflammatory agents (Weyts et al., 1998a; Stolte et al., 2006; Stolte et al., 2008; Teles et al., 2013). In brief, the phagocytic activity of the macrophages parallels NO production and is modulated by LPS and glucocorticoid in opposite direction.

There are few studies on the sympathetic control of immune function in fish (Flory and Bayne, 1991; Narnaware et al., 1994; Castillo et al., 2009; Chadzinska et al., 2012; Kepka et al., 2013). The interaction between adreno-sympathetic and immune systems is highly complex and depends on a variety of factors. Adrenergic receptors (AR) are expressed on immune cells of fish head kidney and leukocytes (Roy and Rai, 2008; Kepka et al., 2013; Nardocci et al., 2014). In the present study, the incubation of the macrophage cultures with $\mathrm{NE}$ and $\mathrm{E}$ did not change the basal nitrite level. Only the $10 \mathrm{nM}$ dopamine stimulated NO production. When the macrophage cultures were co-incubated with LPS and catecholamines, the LPS-induced increase in the NO production was significantly inhibited by $\mathrm{E}$ and NE, but not by dopamine. Adrenergic agonists decreased phagocytosis and epinephrine reduced the production of ROS in rainbow trout head kidney phagocytes, mediated via $\alpha$-adrenergic receptors (Flory and Bayne, 1991; Narnaware et al., 1994). Epinephrine elicits suppressive effects and promotes apoptosis in common carp macrophages (Chadzinska et al., 2012; Kepka et al., 2013). In seabream head kidney preparations (Castillo et al., 2009), $1 \mathrm{~h}$ incubations with epinephrine ( $1 \mathrm{mM})$ inhibited only IL- $1 \beta$ mRNA levels indicating that the pro-inflammatory response of IL- $1 \beta$ can be inhibited by an acute stress situation. After $2 \mathrm{~h}$, IL-1 $\beta$ expression was restored to control levels suggesting that it is rapidly regulated. In murine system, specific $\beta 1$ - or $\beta 2$-adrenergic receptor activation mediates the inhibition of NO by epinephrine but $\alpha$-receptors do not (Sigola and Zinyama, 2000; Zinyama et al., 2001). Catecholamines inhibit the innate and acquired immune response in teleosts through the activation of $\beta$-AR (Roy and Rai, 2008; Nardocci et al., 2014). Excessive production of NO, ROS and pro- and anti-inflammatory cytokines during macrophage activation by LPS or pathogens is harmful to tissues (Kalgraff et al., 2011; Verburg-van Kemenade et al., 2011). The stress hormones like cortisol and $\mathrm{E}$ intervene to regulate the production of these cytokines once the pathogen is cleared.

Concerning the possible mechanisms controlling phagocytosis, pathogens have specific characteristic and well conserved molecules (pathogen-associated molecular patterns-PAMPs) that are important for their virulence and survival and are usually not expressed in the host. The PAMPs are recognized by pathogen-recognition receptors (PRR) expressed on the surface of leukocytes (Verburg-van Kemenade et al., 2011). Toll-like receptors (TLRs), which can be classified into six major families, form one of the best known groups of PRRs (Medzhito 2007). Carp and zebrafish have TLR2 and TLR4 genes in their genomes. TLR4 recognizes LPS of gram positive bacteria (Verburg-van Kemenade et al., 2011). The TLR- mediated recognition of PAMPs trigger downstream cascades leading to the activation of nuclear factor- $\beta \mathrm{B}$ (NF- $\beta \mathrm{B}$ ) and mitogen-activated protein kinase (MAPKs), which control induction of pro-inflammatory mediators like IL- $1 \beta$ and TNF- $\alpha$, chemokines and chemokine receptors. iNOS activity in vitro is detected only after exposure of immune cells to cytokines, LPS or parasites (Nathan 1992; MacMicking et al., 1997; Bogdan 2001). The stimulation of iNOS activity leads to the production of NO, resulting in killing of pathogens and their subsequent engulfing by phagocytosis. The increased secretion of stress hormones like cortisol intervenes to inhibit macrophage activity to maintain homeostasis once the pathogen is neutralized to check further tissue damage. 
In conclusion, catfish HK macrophages elicit phagocytic activity and NO production when challenged with pathogens like LPS. The LPS-induced activation of the macrophages was suppressed by the stress hormones, dexamethasone (cortisol agonist) and $E$ and NE. Dopamine stimulated only the basal level of NO, suggesting differential roles of catecholamines. As the HK is the site for the production of both

\section{References}

Amar E C, Kiron V, Satoh S and Watanabe T (2004) Enhancement of innate immunity in rainbow trout (Oncorhynchus mykiss Walbaum) associated with dietary intake of carotenoids from natural products Fish Shellfish Immunol 16 527-537 (https://www.ncbi.nlm.nih.gov/pubmed/15123294)

Aktan F (2004) iNOS-mediated nitric oxide production and its regulation Life Sci 75 639-653 (https://www.ncbi.nlm.nih. gov/pubmed/15172174)

Arts J A J, Tijhaar E J, Chadzinska M, Savelkoul H F J and Verburg-van Kemenade B M L (2010) Functional analysis of carp interferon- $\gamma$ : Evolutionary conservation of classical phagocyte activation Fish Shellfish Immunol 29 793-802 (https://www.ncbi.nlm.nih.gov/pubmed/20633651)

Barroso J B, Carreras A, Esteban F J, Peinado M A, MartinezLara E, Valderrama R, Jimenez A, Rodrigo J and Lupianez J A (2000) Molecular and kinetic characterization and cell type location of inducible nitric oxide synthase in fish $\mathrm{Am}$ J Physiol Regul Integr Comp Physiol 279 650-656 (http:/ /ajpregu.physiology.org/content/279/2/R650)

Bogdan C (2001) Nitric oxide and the immune response Nat Immunol 2 907-916 (https://www.ncbi.nlm.nih.gov/ pubmed/11577346)

Bonga W (1997) The stress response in fish Physiol Rev 77 591625 (http://repository.ubn.ru.nl/bitstream/handle/2066/ 16774/11067.pdf)

Braun-Nesje R, Kaplan G and Seljelid R (1982) Rainbow trout macrophages in vitro: morphology and phagocytic activity Dev Comp Immunol 6 281-291 (https://www.ncbi.nlm.nih. gov/pubmed/7095232)

Castillo J, Teles M, Mackenzie S and Tort L (2009) Stressrelated hormones modulate cytokine expression in the head kidney of gilthead seabream (Sparus aurata) Fish Shellfish Immunol 27 493-499 (https://www.ncbi.nlm.nih.gov/ pubmed/19591943)

Chadzinska M, Tertil E, Kepka M, Hermsen T, Scheer M and macrophages and stress hormones, it is a potential site for endocrine-immune interactions for maintaining homeostasis of the catfish.

\section{Acknowledgment}

R. K. was a recipient of Rajiv Gandhi National Senior Research Fellowship of UGC, New Delhi, which is gratefully acknowledged.

Verburg-van Kemenade B M (2012) Adrenergic regulation of the innate immune response in common carp (Cyprinus carpio L.) Dev Comp Immunol 36 306-316 (https:// www.ncbi.nlm.nih.gov/pubmed/21641927)

Chi D S, Qui M, Krishnaswamy G, Li C and Stone W (2003) Regulation of nitric oxide production from macrophages by lipopolysaccharide and catecholamines Nitric Oxide $\mathbf{8}$ 127-132 (https://www.ncbi.nlm.nih.gov/pubmed/ 12620376)

Choudhury M G and Saha N (2016) Induction of inducible nitric oxide synthase by lipopolysaccharide and the influences of cell volume changes, stress hormones and oxidative stress on nitric oxide efflux from the perfused liver of air-breathing catfish Heteropneustesfossilis PLoS One 11e 0150469 (http://journals.plos.org/plosone/article?id=10.1371/ journal.pone.0150469)

Cole M A, Kim P J, Kalman B A and Spencer R L (2000). Dexamethasone suppression of corticosteroid secretion: evaluation of the site of action by receptor measures and functional studies Psychoneuro endocrinology 25 151-67 (https://www.ncbi.nlm.nih.gov/pubmed/10674279)

Fast M D, Hosoya S, Johnson S C and Afonso L O B (2008) Cortisol response and immune-related effects of Atlantic salmon (Salmo salar L.) subjected to short- and long-term stress Fish Shellfish Immunol 24 194-204 (https:// www.ncbi.nlm.nih.gov/pubmed/18065240)

Fierro-Castro C, Barrioluengo L, Lopez-Fierro P, Razquin B F, Carracedo B and Villena A J (2012) Fish cell cultures as in vitro models of pro-inflammatory responses elicited by immunostimulants Fish Shellfish Immunol 33 389-400 (https://www.ncbi.nlm.nih.gov/pubmed/22634253)

Fishelson L (2006) Cytomorphological alterations of the thymus, spleen, head-kidney and liver in cardinal fish (Apogonidae, Teleostei) as bioindicators of stress J Morphol 267 57-69 (https://www.ncbi.nlm.nih.gov/pubmed/16247768)

Flory C M and Bayne C J (1991) The influence of adrenergic and cholinergic agents on the chemiluminescent and mitogenic 
responses of leukocytes from the rainbow trout Oncorhynchus mykiss Dev Comp Immunol 15 135-142 (https://www.ncbi.nlm.nih.gov/pubmed/2060683)

Holland J W, Pottinger T G and Secombes C J (2002) Recombinant interleukin-1 beta activates the hypothalamic-pituitaryinterrenal axis in rainbow trout, Oncorhynchus mykiss $J$ Endocrinol 175 261-267 (https://pdfs.semanticscholar.org/ 24af/a16c5e3fc786e89d4f9af9bd316e01259db4.pdf)

Ishibe K, Yamanishi T, Wang Y, Osatomi K, Hara K, Kanai K, Yamaguchi K and Tatsuya O (2009) Comparative analysis of the production of nitric oxide (NO) and tumor necrosis factor- $\alpha$ (TNF- $\alpha)$ from macrophages exposed to high virulent and low virulent strains of Edwardsiella tarda Fish Shellfish Immunol 27 386-389 (https://www.ncbi.nlm. nih.gov/pubmed/19539031)

Jensch-Junior B E, Pressinotti L N, Borges J C S and da Silva J R M C (2006) Characterization of macrophage phagocytosis of the tropical fish Prochilodus scrofa (Steindachner 1881) Aquaculture 251 509-515 (http://www.sciencedirect.com/ science/article/pii/S0044848605003832)

Kalgraff C A K, Wergeland H I and Pettersen E F (2011) Flow cytometry assays of respiratory burst in Atlantic salmon (Salmo salar L.) and in Atlantic cod (Gadus morhua L.) leucocytes Fish Shellfish Immunol 31 381-388 (https:// www.ncbi.nlm.nih.gov/pubmed/21672631)

Kawano H, Kono T, Watanuki H, Savan R and Sakai M (2003) Analysis of genes expressed in head kidney of common carp Cyprinu scarpio L. treated with cortisol Comp Biochem Physiol B Biochem Mol Biol 136 875-886 (https:/ /www.ncbi.nlm.nih.gov/pubmed/14662309)

Kepka M, Verburg-van Kemenade B M L and Chadzinska M (2013) Neuroendocrine modulation of the inflammatory response in common carp: adrenaline regulates leukocyte profile and activity Gen Comp Endocrinol 188 102-109 (https://www.ncbi.nlm.nih.gov/pubmed/23211751)

Kumar R, Joy K P and Singh S M (2016) Morpho-histology of head kidney of female catfish Heteropneustes fossilis: seasonal variations in melano-macrophage centers, melanin contents and effects of lipopolysaccharide and dexamethasone on melanins Fish Physiol Biochem 42 12871306 (https://www.ncbi.nlm.nih.gov/pubmed/26984710)

Laing K J, Hardie L J, Aartsen W, Grabowski P S and Secombes C J (1999) Expression of an inducible nitric oxide synthase gene in rainbow trout Oncorhynchus mykiss Dev Comp Immunol 23 71-85 (http://www.sciencedirect.com/science/ article/pii/S0145305X98000366)

MacKenzie S A, Roher N, Boltana S and Goetz F W (2010) Peptidoglycan, not endotoxin, is the key mediator of cytokine gene expression induced in rainbow trout macrophages by crude LPS Mol Immunol 47 1450-1457 (https://www.ncbi.nlm.nih.gov/pubmed/20304498)

MacMicking J, Xie Q W and Nathan C (1997) Nitric oxide and macrophage function Annu Rev Immunol $15323-350$ (http:/ /www.annualreviews.org/doi/abs/10.1146/annurev. immunol.15.1.323)

Magor B G and Magor K E (2001) Evolution of effectors and receptors of innate immunity Dev Comp Immunol 25 651682 (http://www.sciencedirect.com/science/article/pii/ S0145305X01000295)

Matsche MA and Grizzle J M (1999) Early changes in pigmented macrophages in head kidney of channel catfish infected with Aeromonas hydrophila J Aquat Anim Health 11 253261 (http://www.tandfonline.com/doi/abs/10.1577/ 15488667\%281999\%29011\%3C0253\%3AECIPMI\% 3E2.0.CO\%3B2? journalCode $=$ uahh20)

Maule A G, Tripp R A, Kaattari S L and Schreck C B (1989) Stress alters immune function and disease resistance in chinook salmon (Oncorhynchus tshawytscha) J Endocrinol 120 135-142 (https://www.ncbi.nlm.nih.gov/pubmed/ 2918264)

Medzhitov R (2007) Recognition of microorganisms and activation of the immune response Nature 449 819-826 (https://www.ncbi.nlm.nih.gov/pubmed/17943118)

Mommsen T P, Vijayan M M and Moon T P (1999) Cortisol in teleosts: dynamics, mechanisms of action, and metabolic regulation Rev Fish Biol Fisher 9 211-268 (https:// link.springer.com/article/10.1023/A:1008924418720)

Mulero V and Meseguer J (1998) Functional characterisation of a macrophage-activating factor produced by leucocytes of gilthead seabream (Sparus aurata L.) Fish Shellfish Immunol 8 143-156 (http://agris.fao.org/agris-search/search.do? recordID $=$ GB1997041473)

Nardocci G, Navarro C, Cortes P P, Imarai M, Montoya M, Valenzuela B, Jara P, Acuna-Castillo C and Fernandez R (2014) Neuroendocrine mechanisms for immune system regulation during stress in fish Fish Shellfish Immunol 40 531-538 (http://www.sciencedirect.com/science/article/pii/ S1050464814002861)

Narnaware Y K, Baker B I and Tomlinson M G (1994) The effect of various stresses, corticosteroids and adrenergic agents on phagocytosis in the rainbow trout Oncorhynchus mykiss Fish Physiol Biochem 13 31-40 (https://www.ncbi.nlm. nih.gov/pubmed/24203269)

Nathan C (1992) Nitric oxide as a secretory product of mammalian cells FASEB 6 3051-3064 (https://www.ncbi.nlm.nih.gov/ pubmed/1381691) 
Neumann N F, Fagan D and Belosevic M (1995) Macrophage activating factor(s) secreted by mitogen stimulated goldfish kidney leukocytes synergize with bacterial lipopolysaccharide to induce nitric oxide production in teleost macrophages Dev Comp Immunol 19 473-482 (https://www.ncbi.nlm.nih.gov/pubmed/8773198)

Pelegrin P, Garcia-Castillo J, Mulero V and Meseguer J (2001) Interleukin-1 beta isolated from a marine fish reveals upregulated expression in macrophages following activation with lipopolysaccharide and lymphokines Cytokine $\mathbf{1 6}$ 67-72 (https://www.ncbi.nlm.nih.gov/pubmed/11683587

Pijanowski L, Scheer M, Verburg-van Kemenade B M L and Chadzinska M (2015) Production of inflammatory mediators and extracellular traps by carp macrophages and neutrophils in response to lipopolysaccharide and/or interferon-\$2 Fish Shellfish Immunol 42 473-482 (https:// www.ncbi.nlm.nih.gov/pubmed/25453727)

Pressley M E, Phelan P E III, Witten P E, Mellon M T and Kim C H (2005) Pathogenesis and inflammatory response to Edwardsiella tarda infection in the zebrafish Dev Comp Immunol 29 501-513 (https://www.ncbi.nlm.nih.gov/ pubmed/15752547)

Radomski M W, Palmer R M J and Moncada S (1990) Glucocorticoids inhibit the expression of an inducible, but not the constitutive, nitric oxide synthase in vascular endothelial cells Proc Natl Acad Sci USA 87 10043-10047 (https://www.ncbi.nlm.nih.gov/pubmed/1702214)

Reid S G, Bernier N J and Perry S F (1998) The adrenergic stress response in fish: control of catecholamine storage and release Comp Biochem Physiol C 120 1-27 (http://www.sciencedirect.com/science/article/pii/S0742841398000371)

Ribas J L C, da Silva C A, de Andrade L, Galvan G L, Cestari M M, Trindade E S, Zampronio A R and de Assis H C (2014) Effects of anti-inflammatory drugs in primary kidney cell culture of a freshwater fish Fish Shellfish Immunol 40 296-303 (https://www.ncbi.nlm.nih.gov/pubmed/ 25038277)

Rieger A M, Konowalchuk J D, Grayfer L, Katzenback B A, Havixbeck J J, Kiemele M D, Belosevic M and Barreda D R (2012) Fish and mammalian phagocytes differentially regulate pro-inflammatory and homeostatic responses in vivo PLoS One 7e 47070 (http://journals.plos.org/plosone/ article?id=10.1371/journal.pone.0047070)

Roy B and Rai U (2008) Role of adrenoceptor-coupled second messenger system in sympatho-adrenomedullary modulation of splenic macrophage functions in live fish Channa punctatus Gen Comp Endocrinol 155 298-306 (https://www.ncbi.nlm.nih.gov/pubmed/17574246)
Saeij J P J, Stet R J M, Groeneveld A, Verburg-van Kemenade L B M, van Muiswinkel W B and Wiegertjes G F (2000) Molecular and functional characterization of a fish inducible-type nitric oxide synthase Immunogenetics $\mathbf{5 1}$ 339-346 (https://www.ncbi.nlm.nih.gov/pubmed/ 10803847)

Sarmento A, Marques F, Ellis A E and Afonso A (2004) Modulation of the activity of sea bass (Dicentrarchus labrax) head-kidney macrophages by macrophage activating factor(s) and lipopolysaccharide Fish Shellfish Immunol 16 79-92 (https://www.ncbi.nlm.nih.gov/ pubmed/15123313)

Secombes C J and Fletcher T C (1992) The role of phagocytes in the protective mechanisms of fish Annu Rev Fish Dis 2 53-71 (http://www.sciencedirect.com/science/article/pii/ 0959803092900564)

Sigola LB and Zinyama R B (2000) Adrenaline inhibits macrophage nitric oxide production through $\beta_{1}$ and $\beta_{2}$ adrenergic receptors Immunology 100 359-363 (https://www.ncbi. nlm.nih.gov/pmc/articles/PMC2327023/)

Stave J W and Roberson B S (1985) Hydrocortisone suppresses the chemiluminescent response of striped bass phagocytes Dev Comp Immunol 9 77-84 (https://www.ncbi.nlm. nih.gov/pubmed/3996710)

Stolte E H, Nabuurs S B, Bury N R, Sturm A, Flik G, Savelkoul H F and Verburg-van Kemenade B M (2008) Stress and innate immunity in carp: corticosteroid receptors and proinflammatory cytokines MolImmunol 46 70-79 (https:// www.ncbi.nlm.nih.gov/pubmed/18804866)

Stolte E H, van Kemenade B M, Savelkoul H F and Flik G (2006) Evolution of glucocorticoid receptors with different glucocorticoid sensitivity J Endocrinol 190 17-28 (https:/ /www.ncbi.nlm.nih.gov/pubmed/16837607)

Tafalla C and Novoa B (2000) Requirements for nitric oxide production by turbot (Scophthalmus maximus) head kidney macrophages Dev Comp Immunol 24 623-631 (https:// www.ncbi.nlm.nih.gov/pubmed/10831796

Teles M, Tridico R, Callol A, Fierro-Castro C and Tort L (2013) Differential expression of the corticosteroid receptors GR1, GR2 and MR in rainbow trout organs with slow release cortisol implants Comp Biochem Physiol A MolIntegrPhysiol 164 506-511 (https://www.ncbi.nlm.nih. gov/pubmed/23277222)

Tort L (2011) Stress and immune modulation in fish Dev Comp Immunol 35 1366-1375 (http://www.sciencedirect.com/ science/article/pii/S0145305X11001893)

Verburg-van Kemenade B M L, Groeneveld A, van Rens B T T M and Rombout J H W M (1994) Characterization of 
macrophages and neutrophilic granulocytes from the pronephros of carp (Cyprinus carpio) J exp Biol 187 143158 (https:/www.ncbi.nlm.nih.gov/pubmed/9317515)

Verburg-van Kemenade B M L, Ribeiro C M S and Chadzinska $M$ (2011) Neuroendocrine-immune interaction in fish: differential regulation of phagocyte activity by neuroendocrine factors Gen Comp Endocrinol 172 31-38 (https://www.ncbi.nlm.nih.gov/pubmed/21262228)

Vigliano F A, Bermudez R, Quiroga M I and Nieto J M (2006) Evidence for melano-macrophage centres of teleosts as evolutionary precursors of germinal centres of higher vertebrates: An immunohistochemical study Fish Shellfish Immunol 21 467-471 (http://www.sciencedirect.com/ science/article/pii/S1050464806000052)

Wang R and Bolosevic M (1995) The in vitro effects of estradiol and cortisol on the function of a long-term goldfish macrophage cell line Dev Comp Immunol 19 327-336 (https://www.ncbi.nlm.nih.gov/pubmed/8617403)

Weyts F AA, Cohen N, Flik G and Verburg van-Kemenade B M L (1999) Interactions between the immune system and the hypothalamo-pituitary-interrenal axis in fish Fish Shellfish Immunol 9 1-20 (http://www.sciencedirect.com/science/ article/pii/S105046489890170X)

Weyts F A A, Flik G, Rombout J H W M and Verburg-van Kemenade B M L (1998a) Cortisol induces apoptosis in activated B cells, not in other lymphoid cells of common carp, Cyprinuscarpio L Dev Comp Immunol 22 551-562 (https://www.ncbi.nlm.nih.gov/pubmed/9877436)

Weyts F AA, Flik G and Verburg-van Kemenade B M L (1998b) Cortisol inhibits apoptosis in carp neutrophilic granulocytes Dev Comp Immunol 22 563-572 (https:// www.ncbi.nlm.nih.gov/pubmed/9877437)

Wise D J, Tomasso J R, Schwedler T E, Blazer V S and Gatlin D M III (1993) Effect of vitamin E on the immune response of channel catfish to Edwardsiella ictaluri J Aquat Anim Health 5 183-188 (http://www.tandfonline.com/doi/abs/ 10.1577/1548-8667(1993)005\%3C0183\%3AEOVEOT\% 3E2.3.CO\%3B2)

Yamaguchi T, Watanuki H and Sakai M (2001) Effects of estradiol, progesterone and testosterone on the function of carp, Cyprinus carpio, phagocytes in vitro Comp Biochem Physiol C Toxicol Pharmacol 129 49-55 (https://www.ncbi. nlm.nih.gov/pubmed/11369300)

Yang K, Zhang S, Chen D, Zhang A, Wang X and Zhou H (2013) IFN-y-activated lymphocytes boost nitric oxide production on grass carp monocytes/macrophages Fish Shellfish Immunol 35 1635-1641 (https://www.ncbi.nlm. nih.gov/pubmed/24056277

Yin Z, Lam T J and Sin Y M (1997) Cytokine-mediated antimicrobial immune response of catfish, Clariasgariepinus, as a defence against Aeromonas-hydrophila Fish Shellfish Immunol 7 93-104 (http://www.sciencedirect. com/science/article/pii/S1050464896900662)

Zinyama R B, Bancroft G J and Sigola L B (2001) Adrenaline suppression of the macrophage nitric oxide response to lipopolysaccharides is associated with differential regulation of tumour necrosis factor- $\alpha$ and interleukin-10 Immunology 104 439-446 (https://www.ncbi.nlm.nih.gov/ pubmed/11899430). 